\title{
Estudos morfoanatômicos da semente e da plântula de espécies de Anileiras (Indigofera L., Leguminosae)
}

\author{
Juliana Villela Paulino ${ }^{1}$, Elisângela Pessine ${ }^{2}$ e Simone de Pádua Teixeira ${ }^{3,4}$
}

Recebido em 25/03/2008. Aceito em 1/06/2008

RESUMO - (Estudos morfoanatômicos da semente e da plântula de espécies de anileiras (Indigofera - Leguminosae)). O nome popular "anileira" designa Indigofera anil L., I. suffruticosa Mill. e I. truxillensis Kunth, muito semelhantes quanto à morfologia externa. Este trabalho teve por objetivo avaliar se caracteres da semente e plântula apresentavam valor diagnóstico para este grupo, já que tais caracteres têm sido muito utilizados na Taxonomia de Leguminosae. A superfície e morfoanatomia de sementes e cotilédones foram estudadas por microscopias eletrônica de varredura e de luz, e as etapas do desenvolvimento das plântulas descritas. Embora as plântulas sejam semelhantes, caracteres de sementes (tamanho, forma, ornamentação da superfície, forma do hilo e tamanho do embrião) e cotilédones (forma, organização do parênquima lacunoso na nervura central e distribuição de metabólitos nos tecidos) apresentaram valor diagnóstico para as espécies. I. anil distingue-se de I. suffruticosa por suas sementes maiores e cotilédones com borda acuminada. I. truxillensis caracteriza-se por apresentar sementes cilíndricas e cotilédones reniformes contendo gotas de óleo e alcalóides. Nossos dados, a morfologia externa dos frutos (curvos em I. anil e I. suffruticosa, e retos em I. truxillensis) e, ainda, a anatomia foliar (células parenquimáticas grandes e fenólicas no floema de I. suffruticosa e sua ausência em I. anil) sugerem que I. anil, I. suffruticosa e I. truxillensis não devem ser sinonimizadas.

Palavras-chave: anatomia, cotilédone, histoquímica, Indigofera, semente, taxonomia

ABSTRACT - (Morpho-anatomical studies of seeds and seedlings of wild indigo, "anileira", Indigofera- Leguminosae). The common name "wild indigo" specifies Indigofera anil L., I. suffruticosa Mill. (legitimate name) and I. truxillensis Kunth (legitimate name) that are very similar due to their external morphology. This work analyzed diagnostic characteristics of seeds and seedlings of these species since such features are widely used in taxonomic approaches within Leguminosae. We studied surface features and morpho-anatomy of seeds and cotyledons with scanning electronic microscopy and light microscopy, and described seedling phases. Although seedlings are similar, seed characteristics (size, shape, surface ornamentation, shape of the hilum and embryo size) and cotyledon characteristics (shape, trichome ornamentation, organization of spongy parenchyma along central veins and metabolite distribution in the tissues) have diagnostic features for the species. I. anil differs from I. suffruticosa in its larger seeds and acuminate-margined cotyledons. I. truxillensis is recognized by its cylindrical seeds and kidney-shaped cotyledons with large oil drops. We assume that the characteristics examined, plus fruit morphology and foliar anatomy suggest that I. anil, I. suffruticosa and I. truxillensis should not be synonymized.

Key words: anatomy, cotyledon, histochemistry, Indigofera, seed, taxonomy

\section{Introdução}

O gênero tropical Indigofera L. apresenta cerca de 700 espécies distribuídas nos trópicos e subtrópicos, sendo na maior parte representadas por plantas herbáceas e subarbustivas (Lackey 1981; Lewis et al. 2005). Indigofera é o único gênero da tribo com representantes na flora brasileira, tendo sido listadas nove espécies para o Estado de São Paulo (Moreira \& Tozzi 1997). A este gênero pertence a espécie popularmente conhecida como "Índigo" (I. tinctoria), cuja tintura apresenta grande valor na indústria têxtil (Kamal \& Mangla 1993).

O nome popular "Anileira" designa três espécies de Indigofera com importância econômica: I. anil L., I. suffruticosa Mill. e I. truxillensis Kunth (Bhalla \& Dakwake 1978; Williams 1981; Rao et al. 1984; Garcez et al. 1989; Tokarnia et al. 2000). Embora a raiz, o caule e a folha de I. suffruticosa apresentem propriedades medicinais (Vieira 1992; Martins et al. 2000), empregados como antiespasmódico, sedativo, estomáquico, emenagogo e antídoto contra o Mercúrio e o Arsênico (Martins et al. 2000), a ingestão de partes aéreas causa anemia hemolítica em bovinos (Barbosa Neto et al. 2001). As partes aéreas e a semente de I. anil e I. truxillensis foram consideradas tóxicas em experimentos com bovinos, resultando em taquicardia, anorexia e edema pulmonar (Tokarnia et al. 2000), provavelmente devido à presença do alcalóide indospicina (Aylward et al. 1987).
Indigofera anil, I. suffruticosa e I. truxillensis são espécies muito semelhantes em relação à morfologia externa (ver descrições de Bentham 1862; Burkart 1942; White 1980; Moreira \& Tozzi 1997) e apresentam sobreposição de períodos de floração e de distribuição geográfica (E. Pessine, dados não publicados). Indigofera anil é considerada sinônimo de I. suffruticosa por vários autores (Burkart 1942; White 1980; Kort \& Thijsse 1984; Lewis 1987). Embora estas duas espécies apresentem o mesmo tipo de filotaxia, folíolos numerosos, frutos curvos e reflexos (Bentham 1862; Moreira \& Tozzi 1997), dados de anatomia foliar mostraram alguns caracteres diagnósticos, como a forma das células epidérmicas, a presença de compostos fenólicos e o tipo de mesofilo (G. C. M. C. Barros, dados não publicados).

Características provenientes de plântulas e de sementes têm sido muito utilizadas na Taxonomia e na Sistemática de Leguminosae (Duke \& Polhill 1981; Gunn 1981; Smith 1981). Assim, o presente trabalho teve como objetivo determinar se caracteres morfológicos (externos e internos) provenientes da semente e da plântula apresentam valor taxonômico para as espécies de Indigofera conhecidas popularmente como Anileiras (I. anil, I. suffruticosa e I. truxillensis).

\section{Materiais e métodos}

Sementes de Indigofera anil foram obtidas do Instituto de Zootecnia de Nova Odessa (SP); de I. suffruticosa foram coletadas em Trindade (RJ) e Pratápolis (MG); e de I. truxillensis foram coletadas em Botucatu e

\footnotetext{
1 Universidade de São Paulo, Faculdade de Filosofia, Ciências e Letras de Ribeirão Preto, Ribeirão Preto, SP, Brasil

2 Universidade Estadual Paulista "Júlio de Mesquita Filho", Departamento de Ciências Biológicas, Assis, SP, Brasil

3 Universidade de São Paulo, Faculdade de Ciências Farmacêuticas de Ribeirão Preto, Departamento de Ciências Farmacêuticas, Ribeirão Preto, SP, Brasil

4 Autor para correspondência: spadua@fcfrp.usp.br
} 
Ribeirão Preto (SP). Para cada espécie, foram utilizadas 50 sementes por indivíduo, dois indivíduos provenientes de duas localidades diferentes, totalizando 100 sementes.

Medidas de comprimento e largura das sementes foram realizadas com auxílio de um paquímetro. A forma das sementes baseou-se na razão comprimento-largura, seguindo a terminologia de Hickey (1973) modificada para semente.

Para o acompanhamento das plântulas, as sementes foram colocadas para germinar em placas de petri em temperatura ambiente, após tratamento com solução de hipoclorito de sódio a $15 \%$ por 20 min. e água fervente por 2 min. para a quebra da dormência (Cantliffe et al. 1980; Carpanezzi \& Fowler 1997). Dentre as sementes germinadas, foram obtidas sete plântulas de I. anil, 24 de I. suffruticosa e 10 de I. truxillensis. Paralelamente, 10 sementes de um indivíduo por espécie foram colocadas para germinar diretamente em vasos plásticos pretos (número 4) para a verificação do tipo de germinação de cada espécie.

As etapas do desenvolvimento das plântulas foram estudadas a partir de observações em placas de petri realizadas a cada $12 \mathrm{~h}$. Características morfológicas da raiz, do hipocótilo, do epicótilo e dos cotilédones foram descritas segundo a terminologia adotada por Duke \& Polhill (1981) e Oliveira (2001).

As superfícies das sementes e dos cotilédones emergidos foram examinadas por microscopia eletrônica de varredura. Para tal, estes materiais foram desidratados em série etanólica, submetidos ao ponto crítico em um aparelho Balzers CPD 030, montados em suportes metálicos, colados sobre fita adesiva de carbono e, então, cobertos com Ouro em um metalizador Balzers SCD 050. As observações foram efetuadas no laboratório de Microscopia Eletrônica da Faculdade de Medicina de Ribeirão Preto/USP, em um microscópio eletrônico de varredura JEOL JSM-5200 em 15 kv, e as eletromicrografias obtidas em uma câmera JEOL MP. Para a caracterização da ornamentação da superfície e da morfologia externa, foram adotadas as terminologias de Zeng et al. (2004) e de Ferreira \& Borguetti (2004), respectivamente.
Para o estudo do padrão de venação dos cotilédones, selecionaram-se aqueles perfeitamente desenvolvidos, que foram diafanizados segundo a metodologia proposta por Shobe \& Lersten (1967). Os cotilédones foram colocados em solução aquosa de hidróxido de sódio a $20 \%$, lavados em água destilada e transferidos para solução aquosa de hipoclorito de sódio a $20 \%$ até o clareamento total. Em seguida, foram lavados em água destilada, desidratados em série álcool-xilólica, corados com safranina álcool-xilólica $1 \%$ e montados em resina sintética. A descrição e classificação dos padrões de venação seguiram a terminologia de Hickey (1973).

As análises anatômica e histoquímica foram realizadas em sementes e cotilédones emergidos fixados em FAA 50 por $24 \mathrm{~h}$ (Johansen 1940), lavados em etanol $50 \%$ e estocados em etanol $70 \%$. Em seguida, os materiais foram desidratados em série álcool-xilólica, incluídos em parafina, seccionados ( 8 a $10 \mu \mathrm{m}$ de espessura) em micrótomo rotativo, corados com safranina e azul de astra (Kraus \& Arduin 1997), e submetidos ao reagente de Wagner para alcalóides (Furr \& Mahlberg 1981) e ao cloreto férrico para compostos fenólicos (Johansen 1940). Após a coloração, os cortes foram montados em resina sintética (Gerlach 1969). Cortes a mão livre de material fresco foram submetidos ao sudam III para detecção de substâncias lipofílicas (Johansen 1940) e montados em gelatina glicerinada.

Fotomicrografias foram obtidas em câmera digital Leica DFC 320 acoplada a um microscópio Leica DM 4500 B e a um estereomicroscópio Leica MZ 75.

\section{Resultados}

As sementes de todas as espécies apresentam sulcos, transeto circular e coloração variando de amarela ou castanhoamarelada até marrom escura. $\mathrm{O}$ hilo possui localização central, é visível, heterocrômico; há a presença de para-hilo mais claro (Fig. 1, 4-5, 8-9, 12). A micrópila localiza-se
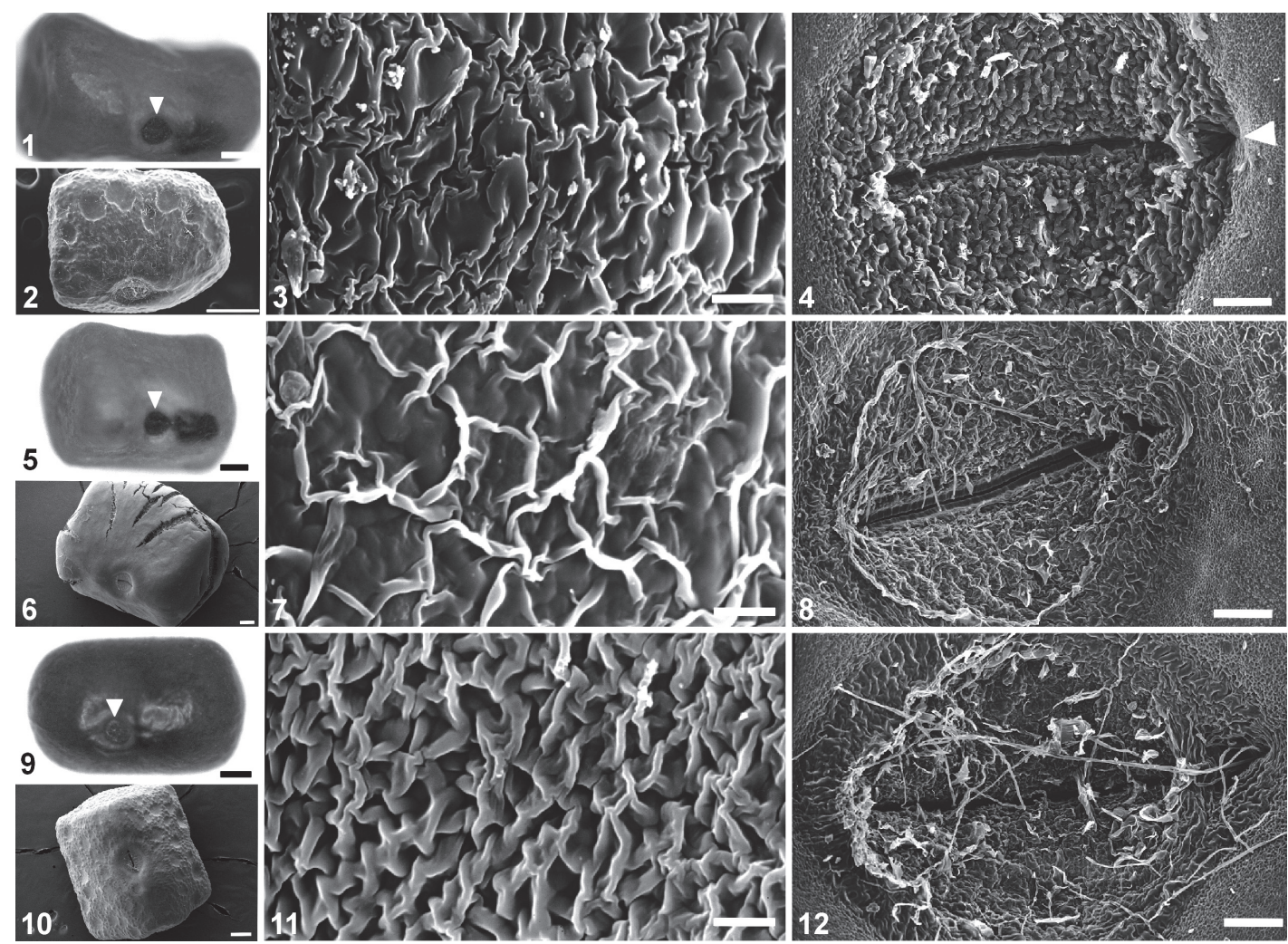

Figuras 1-12. Eletromicrografias (MEV) e fotografias de sementes de espécies de Indigofera. 1-4. I. anil L. 1-2. Sementes inteiras de I. anil. Observe o hilo escuro em 1. 3. Ornamentação das células epidérmicas. 4. Hilo da semente. 5-8. I. suffruticosa Mill. 5-6. Sementes inteiras. Observe o hilo escuro em 5. 7. Ornamentação das células epidérmicas. 8. Hilo da semente. 9-12. I. truxillensis Kunth. 9-10. Sementes inteiras. Observe o hilo mais claro em 9. 11. Ornamentação das células epidérmicas. 12. Hilo da semente. Escalas: $1=415 \mu \mathrm{m} ; 2=500 \mu \mathrm{m} ; 3,7$ e $11=5 \mu \mathrm{m} ; 4,8$ e $12=50 \mu \mathrm{m} ; 5=300 \mu \mathrm{m} ; 6,10=200 \mu \mathrm{m}$; e $9=320 \mu \mathrm{m}$. 
próxima ao hilo, apresenta uma aréola de coloração preta e tamanho grande (Fig. 1, 5, 9). A rafe não é visível. As sementes são endospérmicas e o endosperma possui textura mucilaginosa, consistência firme e coloração semitransparente. O embrião é axial e espatulado; os eixos embrionários são curtos, curvos e cilíndricos (Fig. 13, 14, 15). A testa das sementes é cuticularizada, e constituída por uma camada de macroesclereídes de paredes espessas e por duas a quatro camadas de osteosclereídes. Não há tégmen e nem fibras.

As plântulas de I. anil (Fig. 16-20), I. suffruticosa (Fig. 21-25) e I. truxillensis (Fig. 26-29) apresentam germinação fanero-epigeal, com o tegumento aderido aos cotilédones inicialmente (Fig. 22, 23, 26). Em estádio inicial, a raiz
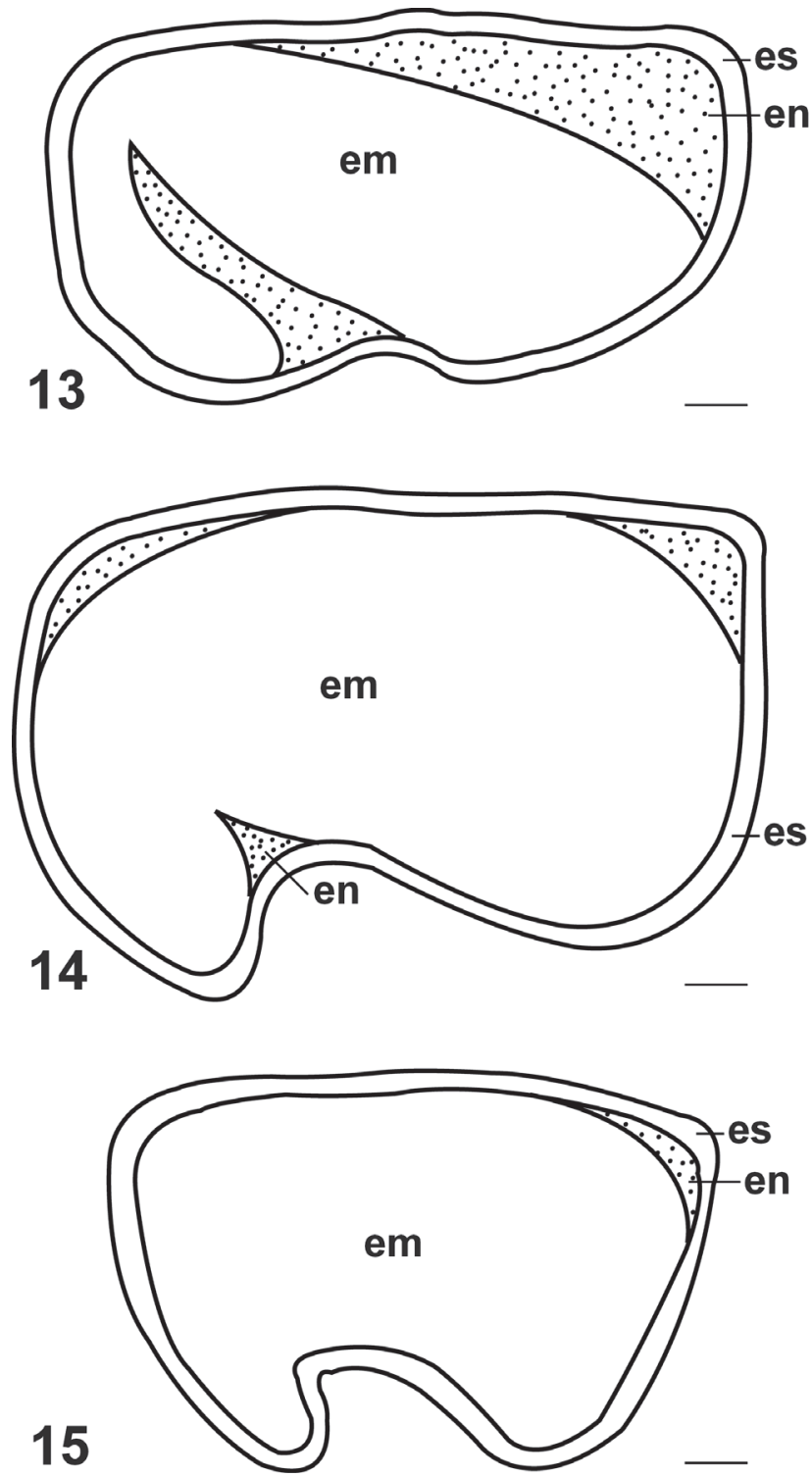

Figuras 13-15. Desenhos esquemáticos de cortes longitudinais medianos de sementes de espécies de Indigofera, evidenciando o tamanho do embrião em relação ao tamanho da cavidade seminal. 13. I. anil L. 14. I. suffruticosa Mill. 15. I. truxillensis Kunth. Símbolos: em $=$ embrião, en $=$ endosperma, es $=$ envoltório seminal. Escalas: $13=334 \mu \mathrm{m} ; 14,15=415 \mu \mathrm{m}$. (Desenhos: Flávia Silva Marquiafável e Rodrigo A. Santinelo Pereira). primária cilíndrica apresenta espessura delgada (Fig. 16, 21, 26), coloração branca, passando a marrom clara conforme se aproxima do colo. O colo é mais claro que o hipocótilo e, em algumas plântulas, apresenta-se mais espesso que o hipocótilo e a raiz (Figs. 18, 22, 23, 27, 28). O hipocótilo cilíndrico é verde-claro, tornando-se mais claro próximo ao colo e mais escuro próximo aos cotilédones. Os cotilédones são foliáceos, fotossintéticos, com margem inteira, ápice obtuso e base levemente acuneada. São esverdeados, sendo a face adaxial mais escura que a face abaxial. Apresentam tricomas tectores em suas regiões basais. Sua epiderme é unisseriada, com estômatos anomocíticos em ambas as faces; o mesofilo é dorsiventral com parênquima paliçádico bisseriado, sendo trisseriado na região próxima aos feixes vasculares e parênquima lacunoso com 4-6 camadas de células (Fig. 30, 32, 34). A nervura central é pouco saliente nas duas faces. $\mathrm{O}$ feixe vascular é colateral e delimitado por uma bainha unisseriada de células parenquimáticas (Fig. 32). A venação é acródroma basal, as aréolas são incompletas com uma terminação, raramente duas; a venação última marginal também é incompleta e ramificada com traqueídes. Os eofilos são unifoliolados, opostos, peciolados (Fig. 19, 20, 25, 29), verdes e membranáceos. Os metafilos são trifoliolados e peciolados (Fig. 20, 25, 29). Posteriormente surgem mais duas folhas pecioladas com cinco folíolos, e em seguida surgem folhas com sete folíolos.

As espécies diferiram quanto ao tamanho (maiores em $I$. truxillensis, seguidas por I. anil, e menores em I. suffruticosa - Tab. 1), à forma (Fig. 1-2, 5-6, 9-10, Tab. 1) e à ornamentação da superfície das sementes (reticulada-buliforme em I. anil - Fig. 3, macrorreticulada em I. suffruticosa - Fig. 7 e microrreticulada em I. truxillensis - Fig. 11), quanto à forma do hilo (Fig. 4, 8, 12, Tab. 1), ao tamanho do embrião na cavidade seminal (não ocupa toda a cavidade seminal em $I$. anil, enquanto em I. suffruticosa e I. truxillensis ocupa toda a cavidade seminal) (Fig. 13-15), à forma e à organização do parênquima lacunoso na região da nervura central dos cotilédones (Figs. 30, 32, 34; Tab. 1). Os tipos de metabólitos encontrados nos cotilédones foram semelhantes nas três espécies, sendo constituídos por óleo e alcalóides, estes últimos associados a grãos de amido. No entanto, a localização destes metabólitos nos parênquimas paliçádico e lacunoso diferiu entre as espécies (Figs. 30, 32, 34; Tab. 2).

\section{Discussão}

Os dados obtidos neste trabalho mostraram que sementes e plântulas de I. anil, I. suffruticosa e I. truxillensis são semelhantes, sendo facilmente reconhecidas em campo por apresentarem: (a) sementes pequenas oblongas, (b) cotilédones foliáceos com margem inteira, (c) eofilos unifoliolados e opostos, (d) primeiros metafilos trifoliolados, e (e) germinação fanero-epigeal, sendo que o tegumento fica aderido aos cotilédones inicialmente. $\mathrm{O}$ reconhecimento das plântulas no campo é importante para espécies de 
16<smiles>CCC=O</smiles>

17

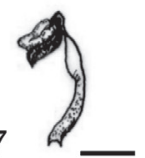

18

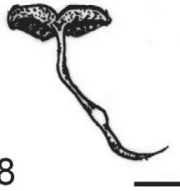

19

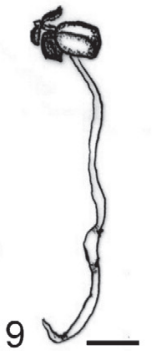

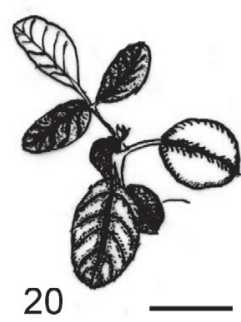

21

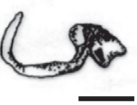

22

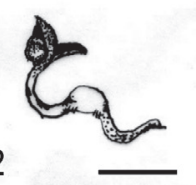

23

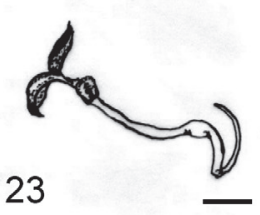

24

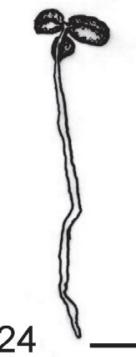

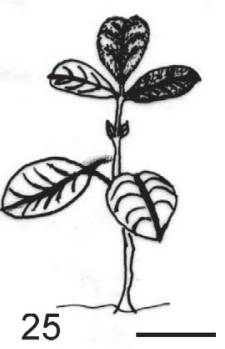

26
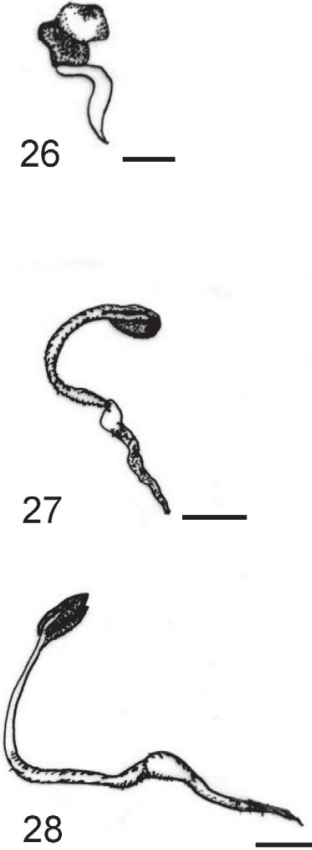

29

Figuras 16-29. Desenvolvimento pós-seminal de espécies de Indigofera (horas ou dias após a germinação). 16-20. I. anil L. 16. 48h. 17. 72h (emissão dos cotilédones). 18. 96h. 19. 13 dias (emissão do primeiro par de eofilos). 20. 26 dias (cultivada em vaso). 21-25. I. suffruticosa Mill. 21. 48 h. 22. 72h (tegumento ainda aderido ao cotilédone, seta). 23. $96 \mathrm{~h}$ (tegumento ainda aderido ao cotilédone, seta). 24. 15 dias. 25. 29 dias (cultivada em vaso). 26-29. I. truxillensis Kunth. 26. 48h (tegumento aderido, seta). 27. 72h. 28. 96h. 29. 27 dias (cultivada em vaso). Símbolos: c = cotilédone, e = eofilo, $\mathrm{m}=\mathrm{metafilo}$. Escalas: $16=1,5 \mathrm{~mm} ; 17=4,4 \mathrm{~mm}$; $18=5 \mathrm{~mm} ; 19=10 \mathrm{~mm} ; 20=11 \mathrm{~mm} ; 21=2 \mathrm{~mm} ; 22=3,25 \mathrm{~mm} ; 23=4 \mathrm{~mm} ; 24=6 \mathrm{~mm} ; 25=14 \mathrm{~mm} ; 26=2,6 \mathrm{~mm} ; 27=2,25 \mathrm{~mm} ; 28=2,7 \mathrm{~mm} ; 29=15 \mathrm{~mm}$. (Desenhos: Flávia Silva Marquiafável).

Indigofera, pois a maioria de seus representantes é considerada tóxica para animais (Williams 1981) e invasora de culturas, pastagens e mesmo de fitofisionomias de Cerrado (Mendonça et al. 1998).

O grande número de espécies que compõem o gênero Indigofera (Polhill 1981; Lewis et al. 2005) dificulta a realização de trabalhos de revisão taxonômica, restringindo as informações a regiões fitogeográficas, como por exemplo, a listagem de Indigofera do sudeste da Ásia (Kort \& Thijsse 1984), da América Central (White 1980), do Brasil - Estado de São Paulo (Moreira \& Tozzi 1997) e Rio Grande do Sul (Eisinger 1987). A regionalização dos estudos, por outro lado, acarreta problemas na delimitação taxonômica das espécies, que passam a apresentar muitos sinônimos, como é o caso de I. suffruticosa.

Embora a morfologia das plântulas de I. anil, I. suffruticosa e I. truxillensis seja bastante semelhante, caracteres provenientes dos cotilédones e das sementes (Tab. 2) apresentaram valor diagnóstico, dos quais destacamos (a) organização das células do parênquima lacunoso na região próxima ao feixe vascular central, (b) distribuição de gotas de óleo e de alcalóides no mesofilo cotiledonar, (c) ornamentação da superfície dos cotilédones e das sementes e (d) formato do hilo (ver Tab. 3). A combinação de caracteres provenientes da microescultura da superfície seminal, da forma e do tamanho do hilo e da semente possibilitou a caracterização de sementes de sete espécies de Indigofera (I. asperifolia, I. bongardiana, I. campestris, I. guaranitica, I. lespedezioides, I. microcarpa e I. spicata - Teixeira \& Corrêa, 2007). Caracteres anatômicos provenientes de cotilédones e eofilos também apresentaram valor diagnóstico em outras espécies de Papilionoideae (tipos de estômatos em cotilédones - Saint-Martin 1979) e Caesalpinioideae (distribuição e tipos de estômatos, e ocorrência de metabólitos em cotilédones e eofilos - Moreira-Coneglian \& Oliveira 2006). Da mesma forma, a ornamentação da superfície de sementes foi considerada bom caráter taxonômico por Zeng et al. (2004). 

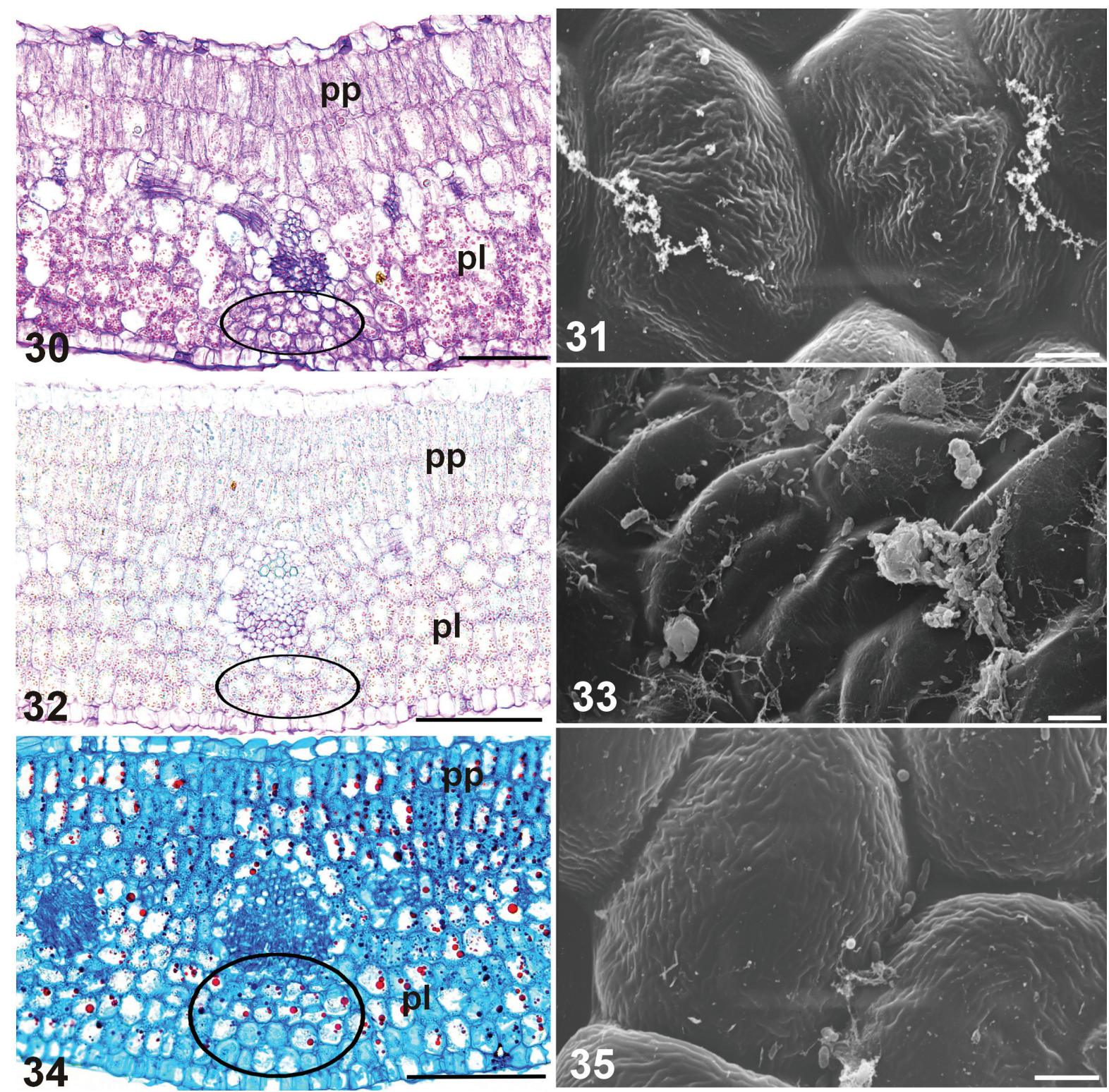

Figuras 30-35. Aspectos estruturais dos cotilédones de espécies de Indigofera. 30-31. I. anil L. 30. Corte histológico da região da nervura central, mostrando grãos de amido nas células do mesofilo e a organização das células do parênquima lacunoso na região abaxial do feixe vascular central (no círculo). 31 . Face adaxial com células papilosas ornamentadas (MEV). 32-33. I. suffruticosa Mill. 32. Corte histológico da região da nervura central mostrando grãos de amido e gotas de óleo nas células do mesofilo. As células do parênquima lacunoso na região do feixe vascular central estão indicadas no círculo. 33 . Face abaxial com superfície levemente ornamentada (MEV). 34-35. I. truxillensis Kunth. 34. Corte histológico da região da nervura central mostrando gotas de óleo nas células do mesofilo. As células do parênquima lacunoso na região do feixe vascular central estão indicadas no círculo. 35. Face adaxial mostrando células epidérmicas papilosas, com ornamentação (MEV). Símbolos: pp = parênquima paliçádico, pl = parênquima lacunoso. Escalas: $30,32,34=43 \mu \mathrm{m} ; 31$ e $35=5 \mu \mathrm{m} ; 33=10 \mu \mathrm{m}$.

Indigofera anil e I. suffruticosa podem ser distinguidas pelo tamanho das sementes, menor em I. suffruticosa, pela borda dos cotilédones, acuminada em $I$. anil e arredondada em I. suffruticosa; I. truxillensis pode ser diagnosticada por suas sementes oblongas muito estreitas, seus cotilédones reniformes contendo gotas de óleo e alcalóides nos parênquimas lacunoso e paliçádico (ver Tab. 1 e 2). Os dados do presente trabalho, a morfologia externa dos frutos (curvos em $I$. anil e $I$. suffruticosa, e retos em I. truxillensis) e, ainda, a anatomia foliar (células parenquimáticas grandes e fenólicas no floema de I. suffruticosa e sua ausência em $I$. anil - G. C. M. C. Barros, dados não publicados) sugerem que a sinonimização de I. anil, I. suffruticosa e I. truxillensis sob o nome I. suffruticosa deve ser re-avaliada.

\section{Agradecimentos}

Este trabalho foi financiado pela FAPESP (processo n ${ }^{\circ}$ 02/11834-5) e realizado nos Laboratórios de Botânica da FCFRP/USP e de Microscopia Eletrônica da FMRP/USP. Agradecemos a Giselle Monte Cassiano Canavaci Barros, José Augusto Maulin, José Gilberto Millani, Maria Dolores Seabra Ferreira, Mário Sadaiti Ogasawara, Rodrigo Augusto Santinelo Pereira, Vani Maria Alves Corrêa, Flávia S. Marquiafável e Edimárcio da Silva Campos pelo auxílio técnico. 
Tabela 1. Caracteres diagnósticos provenientes dos cotilédones e das sementes de Indigofera anil L., I. suffruticosa Mill. e I. truxillensis Kunth.

\begin{tabular}{|c|c|c|c|c|}
\hline Característica & & I. anil & I. suffruticosa & I. truxillensis \\
\hline \multirow{11}{*}{ semente } & comprimento e largura em $\mathrm{mm}$ & $2,48 \pm 0,70 x$ & $2,28 \pm 0,64 x$ & $2,68 \pm 0,57 x$ \\
\hline & $(n=100)$ & $1,0 \pm 0,23$ & $1,1 \pm 0,30$ & $1,1 \pm 0,28$ \\
\hline & comprimento/larogura & 2,4 & 3,5 & 4,7 \\
\hline & 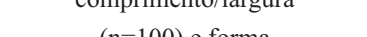 & oblonga & oblonga estreita & oblonga muito estreita \\
\hline & & (Figs. 1, 2) & (Figs. 5, 6) & (Figs. 9, 10) \\
\hline & ornamentacãoda cunerfíci & reticulada-buliforme & macrorreticulada & microrreticulada \\
\hline & ontantentaçau da supenticte & (Fig. 3) & (Fig. 7) & (Fig. 11) \\
\hline & forma do bilo & circular, superficial & ovado, profundo & ovado, profundo \\
\hline & Iorma do nilo & (Fig. 4) & (Fig. 8) & (Fig. 12) \\
\hline & & não ocupa toda a cavidade & ocupa toda a cavidade & ocupa toda a cavidade seminal \\
\hline & embriao & seminal (Fig. 13) & seminal (Fig. 14) & (Fig. 15) \\
\hline \multirow{4}{*}{ cotilédone } & forma & obovada & obovada & reniforme \\
\hline & borda em corte transversal & acuminada & arredondada & $\begin{array}{l}\text { assimétrica: acuminada de um } \\
\text { lado e arredondada de outro }\end{array}$ \\
\hline & organização do parênquima & sim (Fig. 30) & não (Fig. 32) & não (Fig. 34) \\
\hline & $\begin{array}{c}\text { forma e ornamentação das células } \\
\text { epidérmicas }\end{array}$ & $\begin{array}{l}\text { papilosas reticuladas } \\
\text { (Fig. 31) }\end{array}$ & $\begin{array}{l}\text { retangulares lisas } \\
\text { (Fig. 33) }\end{array}$ & $\begin{array}{c}\text { retangulares na face abaxial e } \\
\text { papilosas reticuladas na adaxial } \\
(\text { Fig. } 35)\end{array}$ \\
\hline
\end{tabular}

Tabela 2. Metabólitos detectados nas células dos cotilédones de Indigofera anil L., I. suffruticosa Mill. e I. truxillensis Kunth. Os sinais - e + indicam negativo e positivo, respectivamente.

\begin{tabular}{lccccc}
\hline \multirow{2}{*}{ Metabólitos } & \multicolumn{2}{c}{ I. anil (Fig. 30) } & & I. suffruticosa (Fig. 32) & I. truxillensis (Fig. 34) \\
\cline { 2 - 5 } & Paliçádico & Lacunoso & Paliçádico & Lacunoso & Paliçádico \\
\hline Óleo & + & + & + & - & Lacunoso \\
Alcalóides & - & + & + & + \\
Compostos Fenólicos & - & - & - & - \\
\hline
\end{tabular}

\section{Referências bibliográficas}

Aylward, J.H.; Court, R.D.; Haydock, K.P.; Strickland, R.W. \& Hegarty, M.P. 1987. Indigofera spp. with agronomic potential in the tropics: rat toxicity studies. Australian Journal of the Agricultural Research 38: $177-186$.

Barbosa Neto, J.D.; Oliveira, C.M.C.; Peixoto, P.V.; Barbosa, I.B.P.; Ávila, S.C. \& Tokarnia, C.H. 2001. Anemia hemolítica causada por Indigofera suffruticosa (Leg. Papilionoideae) em bovinos. Pesquisa Veterinária Brasileira 21: 18-22.

Bentham, G. 1862. Indigofera. Pp. 36-42. In: C.F.P. Martius (ed.). Flora Brasiliensis. Lipsiae, Frid. Fleischer. Pars 1.

Bhalla, N.P. \& Dakwake, R.N. 1978. Chemotaxonomy of Indigofera Linn. Journal of Indian Botanical Society 57: 180-185.

Burkart, A. 1942. Las especies de Indigofera de la Flora Argentina. Darwiniana 4: 145-178.

Cantliffe, D.J.; Tang, A.C. \& Guedes, A.C. 1980. Seed treatment of hairy indigo (Indigofera hirsuta L.) to overcome hard seed dormancy. HortScience 15: 518-520.

Carpanezzi, A.A. \& Fowler, J.A.P. 1997. Tratamentos pré-germinativos para sementes de anileira. Documentos Embrapa 12: 1-3.

Duke, J.A. \& Polhill, R.M. 1981. Seedlings of Leguminosae. Pp. 941949. In: R.M. Polhill \& P.H. Raven (eds.). Advances in Legume Systematics. Kew, Royal Botanic Gardens.
Eisinger, S.M. 1987. O Gênero Indigofera L. (Leguminosae-PapilionoideaeIndigofereae) no Rio Grande do Sul - Brasil. Acta Botanica Brasilica 1: $123-140$

Ferreira, A.G. \& Borghetti, F. 2004. Germinação: do Básico ao Aplicado. Porto Alegre, Artmed.

Furr, M. \& Mahlberg, P.G. 1981. Histochemical analysis of lacticifers and glandular trichomes in Cannabis sativa. Journal of Natural Products 44: 153-159.

Garcez, W.S.; Garcez, F.R.; Honda, N.K. \& Silva, A.J.R. 1989. A nitropraponoyl-glucopyranoside from Indigofera suffruticosa. Phytochemistry 28: 1251-1252.

Gerlach, G. 1969. Botanische Mikrotechnik, eine Einfuhrung. Stuttgart, Gorg Thieme.

Gunn, C.R. 1981. Seeds of Leguminosae. Pp. 913-925. In: R.M. Polhill \& P.H. Raven (eds.). Advances in Legume Systematics. Kew, Royal Botanic Gardens.

Hickey, L. 1973. Classification of the architecture of dicotyledonous leaves. American Journal of Botany 60: 17-33.

Johansen, D.A. 1940. Plant microtechnique. New York, McGraw-Hill Book Company Inc.

Kamal, R. \& Mangla, M. 1993. In vivo and in vitro investigations on rotenoids from Indigofera tinctoria and their bioefficacy against the larvae of Anopheles stephensi and adults of Callosobruchus chinensis. Journal of Bioscience (Bangalore) 18: 93-101. 
Kort, I.D. \& Thijsse, G. 1984. A Revision of the Genus Indigofera (Leguminosae-Papilionoideae) in Southeast Asia. Blumea 30: 89-151.

Kraus, J.A. \& Arduin, M. 1997. Manual básico de métodos em morfologia vegetal. Seropédica, Universidade Federal Rural do Rio de Janeiro.

Lackey, J.A. 1981. Phaseoleae. Pp. 301-327. In: R.M. Polhill \& P.H Raven (eds.). Advances in Legume Systematics. Kew, Royal Botanic Gardens.

Lewis, G.P. 1987. Legumes of Bahia. Kew, Royal Botanic Gardens.

Lewis, G.; Schrire, B.; Mackinder, B. \& Lock, M. 2005. Legumes of the World. Kew, Royal Botanic Gardens.

Martins, E.R.; Castro, D.M.; Castellani, D.C. \& Dias, J.E. 2000. Plantas medicinais. Viçosa, UFV.

Mendonça, R.C.; Felfili, J.M.; Walter, B.M.T.; Silva Junior, M.C.; Resende, A.V.; Filgueiras, T.S. \& Nogueira, P.E. 1998. Flora vascular do Bioma Cerrado. Pp.287-556. In: S.M. Sano \& S.P. Almeida (eds.). Cerrado: Ambiente e Flora. Planaltina, Embrapa.

Moreira J.L.D. \& Tozzi A.M.G. 1997. Indigofera L. (Leguminosae, Papilionoideae) no estado de São Paulo, Brasil. Revista Brasileira de Botânica 20: 97-117.

Moreira-Coneglian, I.R. \& Oliveira, D.M.T. 2006. Anatomia comparada dos limbos cotiledonares e eofilares de dez espécies de Caesalpinioideae (Fabaceae). Revista Brasileira de Botânica 29: 193-207.

Oliveira D.M.T. 2001. Morfologia comparada de plântulas e plantas jovens de leguminosas arbóreas nativas: espécies de Phaseoleae, Sophoreae, Swartzieae e Tephrosieae. Revista Brasileira de Botânica 24: 85-97.
Polhill, R.M. 1981. Indigofereae. Pp.289-291. In: R.M. Polhill \& P.H. Raven (eds.). Advances in Legume Systematics. Kew, Royal Botanic Gardens.

Rao, J.U.M.; Hanumaiah, T.; Rao, B.K. \& Rao, K.V.J. 1984. A new flavonol glycoside from the leaves of Indigofera hirsuta Linn. Jounal of Indian Chemical Society 23B: 91.

Saint-Martin, M. 1979. Types stomatiques des plantules de Papilionacées. Bulletin de la Société Botanique Française 3: 85-91.

Shobe, W.R. \& Lersten, N.R. 1967. A technique for clearing and staining gymnosperm leaves. Botanical Gazette 127: 150-152.

Smith, D.L. 1981. Cotyledons of the Leguminosae. Pp. 927-940. R.M. Polhill \& P.H. Raven (eds.). Advances in Legume Systematics. Kew, Royal Botanic Gardens.

Teixeira, S.P. \& Corrêa, V.M.A. 2007. Morfoanatomia do envoltório seminal de espécies brasileiras de Indigofera L. (Leguminosae, Papilionoideae). Rodriguésia 58: 265-273.

Tokarnia, C. H.; Döbereiner, J. \& Peixoto, P.V. 2000. Plantas tóxicas do Brasil. Rio de Janeiro, Editora Helianthus.

Vieira, L.S. 1992. Fitoterapia da Amazônia, Manual de Plantas Medicinais. $2^{\mathrm{a}}$ ed. São Paulo, Editora Agronômica Ceres.

White, P.S. 1980. Indigofera. Annals of Missouri Botanical Garden 67: 706-714.

Williams, M.C. 1981. Nitro compounds in Indigofera species. Agronomy Journal 73: 434-436.

Zeng, C-L.; Wang, J-B.; Liu, A-H. \& Wu, X-M. 2004. Seed coat microsculpturing changes during seed development in diploid and amphidiploid Brassica species. Annals of Botany 93: 555-566.

Versão eletrônica do artigo em www.scielo.br/abb e http://www.botanica.org.br/acta/ojs 